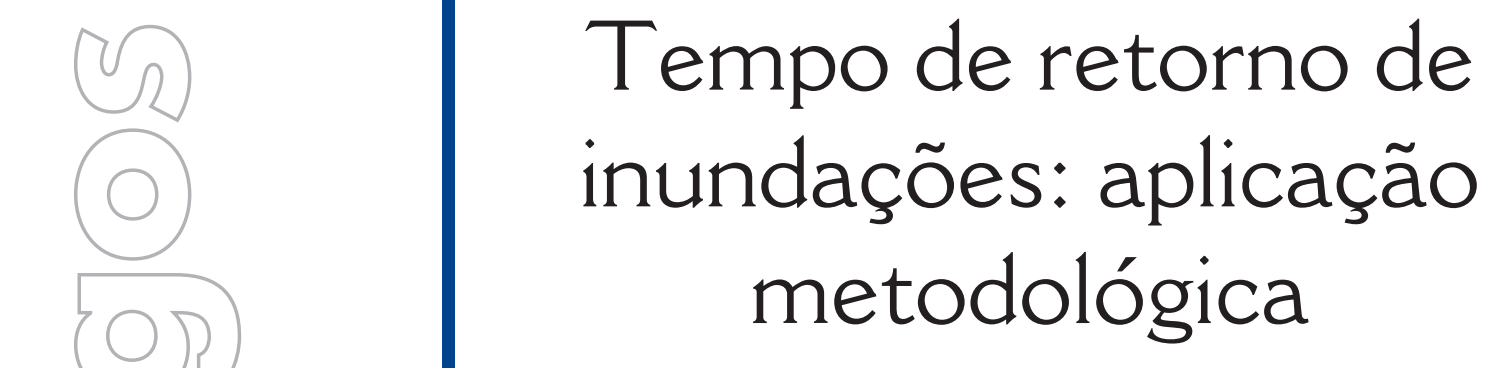

Bruno Zucuni Prina

UFSM

Romario Trentin

UFSM

p. $670-686$

\section{revista}

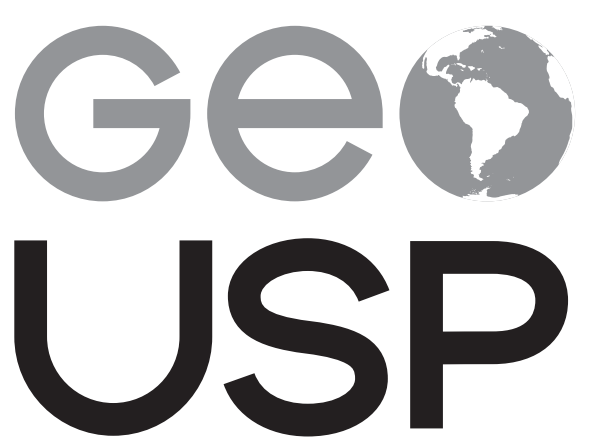

espaço e tempo

Volume 22 - $n^{\circ} 3(2018)$
Como citar este artigo:

PRINA, B. Z.; TRENTIN, R. Tempo de retorno de inundações: aplicação metodológica. Geousp - Espaço e Tempo (Online), v. 22, n. 3, p. 670-686, dez. 2018. ISSN 2179-0892.

Disponível em: <https://www.revistas.usp.br/geousp/article/view/145266>. doi: http://dx.doi.org/10.11606/issn.21790892.geousp.2018.145266.

\section{(c) ()}

Este artigo está licenciado sob a Creative Commons Attribution 4.0 License. 


\title{
Tempo de retorno de inundações: aplicação metodológica
}

\section{Resumo}

Esse trabalho visa estimar o tempo de retorno das inundações urbanas no município de Jaguari-RS. $O$ processo metodológico adotado fez uso dos dados das réguas milimétricas obtidas na Agência Nacional de Águas (ANA), e, com o aplicativo Pesquisas HidroWeb, foi possível sintetizar os dados a fim de obter amostras do tempo de retorno das inundações. Para tanto, usaram-se seis funções matemáticas no aplicativo Excel para prever o tempo de retorno e depois comparar os dados para obter a melhor estimativa. Entre várias informações obtidas, compararam-se: a correlação entre as amostras e os dados estimados, por meio do coeficiente de correlação linear de Pearson $\left(R^{2}\right)$, e o desvio padrão dos resíduos. Por meio das várias análises, constatou-se que a função que melhor modela o tempo de retorno das inundações urbanas na área de estudo é a logarítmica, por gerar o maior $\mathrm{R}^{2}$ e o menor desvio padrão dos resíduos.

Palavras-chaves: Coeficiente de correlação linear de Pearson. Tempo de retorno. Inundações urbanas.

\section{Flood return time: methodological application}

\begin{abstract}
This paper has the purpose to perform the estimated time of return for urban floods in the city of Jaguari, Brazil. The methodological process of this paper occurred with use the data from millimeter rulers obtained from the Agência Nacional de Águas (ANA), and, thus, with the utilization of app Pesquisas HidroWeb, it was synthesized for the purpose data to obtain samples of time of return for floods. It was used six mathematical functions, from Excel, in order to predict the time of return and subsequently comparing the data, obtaining the best estimate. Like this, between various information obtained, were compared: the correlation between the samples and the estimated data through the Linear Correlation Coefficient of Pearson $\left(\mathrm{R}^{2}\right)$ and the standard deviation of residues. Therefore, from the various analyzes, was observed that the function better modeling the estimate of time of return in the study area is Logarithmic, for generating the highest $R^{2}$ and standard deviation of the lowest of residues.
\end{abstract}

Keywords: Linear Correlation Coefficient Pearson. Time of return. Urban Flooding. 


\section{Introdução}

Entre os inúmeros assuntos que estão em destaque na mídia (reportagens) e na comunidade científica (produções acadêmicas), ultimamente, muitos referem-se a problemas oriundos de desastres naturais, boa parte relativa a inundações urbanas. Tais eventos são comuns em meios informativos, e sua frequência, assim seus danos, são vivamente acentuados com o passar do tempo. Destaca-se o agravamento desse problema com a urbanização, que reduz os processos de infiltração da água no solo (mais impermeabilização de calçadas, ruas etc.), levando a um maior escoamento superficial e, logo, um maior aporte de água nos corpos hídricos.

processo ainda é impulsionado pela localização, muitas vezes de ocupação de baixa renda (mais vulnerável) em posições geográficas propícias a inundações (áreas suscetíveis) como, por exemplo, áreas ribeirinhas, formado áreas de perigo (pela presença populacional), as quais depois serão essenciais para dimensionar o zoneamento do risco.

Por mais que no Brasil não haja incidência de desastres naturais de origem tectônica, Santos (2007, p. 10) alerta que em nosso país "os desastres tendem a estar relacionados a fenômenos climáticos, potencializados pela ação do homem". Segundo dados descritos pelo mesmo autor, no período de 2000 a 2007 foram registrados cerca de 36 grandes episódios de desastres naturais (enchentes, secas e deslizamentos de terra) no Brasil, com mais de 1,5 milhões de pessoas afetadas, estimando ao país um prejuízo econômico na ordem de US\$ 2,5 bilhões. Uma explicação sucinta dos grandes prejuízos no país é dada por Santos (2007, p. 11): "o uso impróprio dos recursos naturais, a ocupação de áreas com maior suscetibilidade natural e o desmatamento são, no Brasil, os principais fatores que potencializam a ocorrência de desastres naturais".

Para entender esse trabalho, é necessária a fundamentação teórica de alguns conceitos subjacentes às questões metodológicas adotadas. Assim, inicialmente, defini-se tempo de retorno e se contextualiza o conceito perante as inundações.

Contribuem Tucci e Bertoni (2003) explicando que o tempo de retorno é o inverso da probabilidade de ocorrência do fenômeno, representando o tempo médio em que o evento se poderá replicar. A metodologia de Tucci (1993, p. 640) expressa que "a escolha do tempo de retorno é arbitrária e depende da definição do futuro zoneamento". Ou seja, conforme o resultado obtido no tempo de retorno (a cota altimétrica correspondente a determinado tempo de retorno), o futuro zoneamento (do risco) estará atrelado a essa questão.

Ainda quanto ao termo, o Instituto Geológico de São Paulo (2012) explica que a variável denominada risco à inundação (para uma determinada população) é intimamente ligada ao tempo de retorno de um evento. Assim, é notória a importância da estimativa do tempo de retorno, pois essa variável delimita um futuro zoneamento da área de estudo, delimitando as áreas com diferentes graus de risco.

Tucci (1993) destaca que é essencial o levantamento topográfico das áreas de risco de inundação com tempo de retorno menor ou igual a 100 anos, verificando que esse é um ponto limítrofe para zonear áreas de risco, depois do que se pode, por exemplo, classificar o risco como não considerado ou sem estimativa de risco.

Um fator de destaque, verificando e contextualizando informações referentes ao tempo de retorno, é que "de uma forma geral as atividades humanas contribuem diretamente para o aumento da probabilidade de ocorrência de inundações e dos impactos negativos associados" (Cunha; Taveira-Pinto, 2011, p. 106), aumentando o tempo de retorno dos eventos. 
É importante também definir suscetibilidade, perigo, vulnerabilidade e risco, pois esses conceitos estão intimamente ligados ao desenvolvimento de pesquisas sobre o tema, de modo que entender essa terminologia é essencial como técnico-conceitual.

Ribeiro e Lima (2011) destacam que a previsão e o mapeamento dos locais com maiores proporções suscetíveis à ocorrência de inundações são essenciais para a caracterização da superfície, gerando, assim, o zoneamento urbano e a escolha das melhores áreas para locação de obras de drenagem com o intuito de minimizar os danos à população.

Campos et al. (2015) discutem a necessidade do mapeamento de áreas suscetíveis juntamente com a análise territorial. Sobre essa questão, o IPT (2016, p. 1) salienta que:

[...] o conhecimento prévio das suscetibilidades dos terrenos à geração e desenvolvimento de fenômenos e processos do meio físico cuja dinâmica pode ocasionar desastres naturais é de grande importância aos municípios, contribuindo para o planejamento do uso e ocupação do solo, controle da expansão urbana, avaliação de cenários potenciais de riscos e, ainda, no âmbito regional, auxiliar na elaboração de zoneamentos ecológico-econômicos.

Para a Defesa Civil (Castro, 1998, p. 123) pode ser definida como perigo "qualquer condição potencial ou real que pode vir a causar morte, ferimento ou dano à propriedade".

Contribui Ayala-Carcedo (2000) informando que a conceituação de perigo (ou do espanhol peligro) deve-se adotar como variável principal de análise a velocidade de acontecimento (tempo de retorno).

Para a construção cartográfica do perigo (do mapa de perigo), Leonardo Monteiro e Kobiyama (2013) explicam que o uso do tempo de retorno é essencial para caracterizar e delimitar as áreas, ou seja, para evidenciar o perigo de cada lugar. Os autores ainda referem que o mapa de inundação também está ligado ao tempo de retorno e que a modelagem dos dados está intimamente ligada ao Modelo Digital de Elevação (MDE), interferindo no resultado e na qualidade final da cartografia gerada.

A seguir será abordado o conceito de vulnerabilidade. Uma população ser mais ou menos vulnerável tem relação direta com sua capacidade de enfrentar um desastre e assimilar imediatamente seus impactos (Carvalho, D.; Damacena, 2013).

A vulnerabilidade também pode ser definida como um fator ligado à intensidade de um evento perigoso (Ayala-Carcedo, 2000).

Já o conceito de áreas de risco, segundo o IPT (1991), envolve os lugares onde há possibilidade de perigo, perda ou dano social ou econômico, estando a população exposta em caso de ocorrência de processos físicos naturais.

Citando Gallais (1994), ' Susana Aneas de Castro (2000) sugere definir risco como a probabilidade de se concretizar uma ameaça, atrelando a ideia de o conceito aproximar os fenômenos naturais e o homem.

A Defesa Civil (Castro, 1998, p. 147) apresenta cinco ramificações para definir risco:

(1) Medida de dano potencial ou prejuízo econômico expressa em termos de probabilidade estatística de ocorrência e de intensidade ou grandeza das conseqüências previsíveis. (2) Probabilidade de ocorrência de um acidente ou evento adver-

1 GALLAIS, J. Les tropiques, terres de risques et de violences. Paris: Armand Colin, 1994. 
so, relacionado com a intensidade dos danos ou perdas, resultantes dos mesmos. (3) Probabilidade de danos potenciais dentro de um período especificado de tempo e/ou de ciclos operacionais. (4) Fatores estabelecidos, mediante estudos sistematizados, que envolvem uma probabilidade significativa de ocorrência de um acidente ou desastre. (5) Relação existente entre a probabilidade de que uma ameaça de evento adverso ou acidente determinado se concretize e o grau de vulnerabilidade do sistema receptor a seus efeitos.

Ayala-Carcedo (2000) especifica que os fatores necessários para o risco são três: o perigo, a vulnerabilidade e a exposição. $\bigcirc$ perigo é o fator, ou o conjunto de fatores que tornam o evento mais grave. A exposição refere-se ao conjunto de pessoas (e de seus bens) que estão expostos a uma situação de perigo. Já a vulnerabilidade é considerada uma variável associada ao grau de perdas e danos à população sujeita a um perigo.

Segundo Aneas de Castro (2000), a concepção mais aceita entre os pesquisadores é a do risco como o perigo que ocorre ou a probabilidade de que aconteça determinado evento perigoso.

Com a metodologia de Khatibi (2011), quantifica-se o risco por meio de um resultado matemático obtido pelo cruzamento da probabilidade com o perigo. Assim, verifica-se que todo o zoneamento do risco passa pela interação de diferentes bases cartográficas, dada a complexidade de informações.

Em linhas gerais, esta pesquisa visa trabalhar com o tempo de retorno de inundações. Assim, uma vez definidos vários conceitos, é preciso explicar o que é inundação; para a Defesa Civil (Castro, 1998, p. 96), consiste no "transbordamento de água da calha normal de rios, mares, lagos e açudes, ou acumulação de água por drenagem deficiente, em áreas não habitualmente submersas". Outro conceito similar ao de inundação, e que perpassa por muita confusão teórica, refere-se ao de enxurrada. $\bigcirc$ conceito de enxurrada pode ser tomado de Tominaga, Santoro e Amaral (2009, p. 42): "escoamento superficial concentrado e com alta energia de transporte, que pode ou não estar associado a área de domínio dos processos fluviais". Analogamente, Celso Carvalho, Macedo e Ogura (2007) explicam que as enxurradas são caracterizadas pelo escoamento superficial concentrado e com alta energia de transporte.

Hoje, muitos trabalhos com desastres ambientais dispõem de um grande arcabouço tecnológico, principalmente com o uso da geoinformação. Câmara e Antônio Miguel Monteiro (2000) afirmam que a geoinformação pode ser uma grande solução para o planejamento municipal, pois muitos setores públicos podem dispor de sistemas eficientes, e haverá formas de atualização do cadastro municipal, sendo um ato muito inteligente da administração pública.

A área de estudo deste trabalho está situada no perímetro urbano do município de Jaguari (Mapa 1), situado no centro-oeste do estado do Rio Grande do Sul e banhado pelo rio Jaguari, afluente do Ibicuí. Jaguari é conhecida como "a cidade das belezas naturais", pois seu povo hospitaleiro preserva muito bem suas diversas belezas naturais).

Quanto ao município de Jaguari, sua população total é de cerca de 11,5 mil habitantes, numa área de aproximadamente $673 \mathrm{~km}^{2}$, resultando numa densidade demográfica de 17,04 habitantes $/ \mathrm{km}^{2}$. Da população residente do município de Jaguari, 57\% está no meio urbano e $43 \%$ no perímetro rural (IBGE, 2010). 
Conforme o levantamento realizado por Reckziegel (2007) entre 1980 e 2005, o município de Jaguari registrou três eventos de enchentes, sendo eles em: outubro/1982, outubro/1997 e abril/1998. A mesma autora quantificou no mesmo período três cenários de enxurradas, registradas em maio/1984, novembro/1997 e outubro/2002. Para salientar problemas com inundações em Jaguari, Reckziegel (2007, p. 136) enfatiza que, em maio de 1984, "os danos mais significativos ocorreram em municípios dos vales dos rios Jaguari e lbicuí e da porção oeste do estado". A autora ainda destaca que mais de 100 edificações foram completamente destruídas e aproximadamente 150 danificadas, ocasionando duas mortes, além de cerca de 1.500 desabrigados no município. Outro grande evento que prejudicou a cidade ocorreu em outubro de 1997, desabrigando cerca de 890 pessoas (Reckziegel, 2007).

\section{Mapa 1 - Localização da área de estudo}

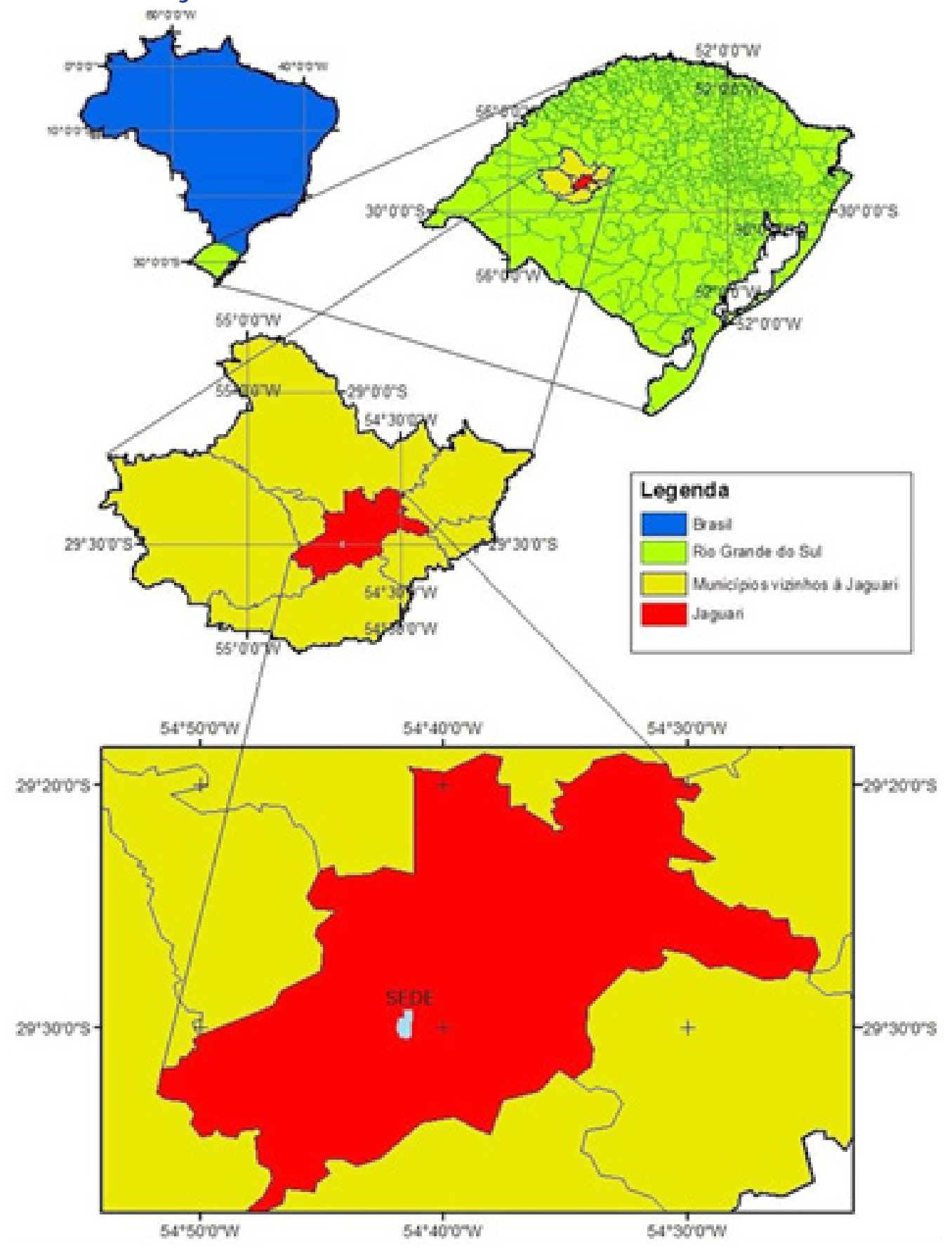


Após o ano de 2005, limite do trabalho de Reckziegel (2007), o município de Jaguari sofreu ainda três inundações. A primeira, em janeiro de 2010, a segunda, em outubro de 2012, e a última, em julho de 2014, como comprovam relatos da mídia. Na primeira data, o jornal Correio do Povo (Cerca [...], 2010) destaca que cerca de 30 famílias ficaram desabrigadas por causa do evento. Na segunda, segundo o jornal Diário de Santa Maria (Diário [...], 2012), alguns moradores foram removidos de suas residências em função da invasão da água. Por fim, na terceira data, após um alto índice de precipitação, a inundação no rio Jaguari alagou parcialmente alguns bairros (Enchente [...], 2014).

Assim, fica claro o problema que o município enfrenta nesse cenários de perdas devido às inundações. No que tange ao assunto, o Atlas de vulnerabilidade a inundações (ANA, [s.d.]) esclarece que, no estado do Rio Grande do Sul, o trecho do rio Jaguari que passa pelo perímetro urbano do município é classificado como de "alta vulnerabilidade a inundações". Já Robaina e Trentin (2013) classificaram Jaguari como um município com média probabilidade de ocorrência de inundações, de modo que é preciso identificar e mapear detalhadamente os locais com maiores porções suscetíveis.

Portanto, o problema deste artigo é saber como estimar o tempo de retorno de inundações urbanas no município de Jaguari-RS.

Assim, justifica-se a necessidade de entender que, com a estimativa do tempo de retorno do evento, trabalhos futuros poderão limitar as áreas para coleta de dados altimétricos visando a construção de um MDE do perímetro urbano do município, para um posterior zoneamento do risco. $\bigcirc$ objetivo geral do trabalho é desenvolver uma metodologia para estimar o tempo de retorno de inundações urbanas no município de Jaguari-RS. Mais especificamente:

- criar um aplicativo para apoiar o cálculo da estimativa do tempo de retorno das inundações em Jaguari-RS;

- usar funções estatísticas para estimar o tempo de recorrência de inundações;

- identificar a melhor função para estimar o tempo de retorno na área de estudo;

- estimar o tempo de retorno de inundações urbanas.

\section{Material}

Antes de segmentar os procedimentos metodológicos envolvidos nesse trabalho, há de citar os aplicativos os quais foram utilizados. Assim, utilizaram-se: o Access, o Excel e o Pesquisas HidroWeb, desenvolvido por um dos autores, por meio da linguagem de programação Visual Basic.

Os dados que serviram às análises foram obtidos no sítio da Agência Nacional de Águas (ANA), na extensão denominada HidroWeb (ANA, [s.d]), e referem-se ao nível da água do rio Jaguari disposto nas réguas milimétricas do município (Figura 1).

Destaca-se que os dados obtidos estão situados desde novembro de 1941 a fevereiro de 2014, numa escala temporal de 73 anos. Infere-se ainda, que a tabela original do HidroWeb continha inúmeras informações, como por exemplo, a cota do rio (referente às réguas milimétricas) para todos os dias (nos 73 anos).

Em face da grande quantidade de dados, decidiu-se usar apenas uma das colunas da tabela original, a que correspondia ao nível máximo que a água do rio alcançou nas réguas no intervalo de um mês. Portanto, os dados em análise referem-se a uma escala temporal variante no mês, verificando a cota máxima de cada um desses períodos. 
Figura 1 - Réguas de milimetragem do nível do rio Jaguari, localizadas no balneário Fernando Schiling

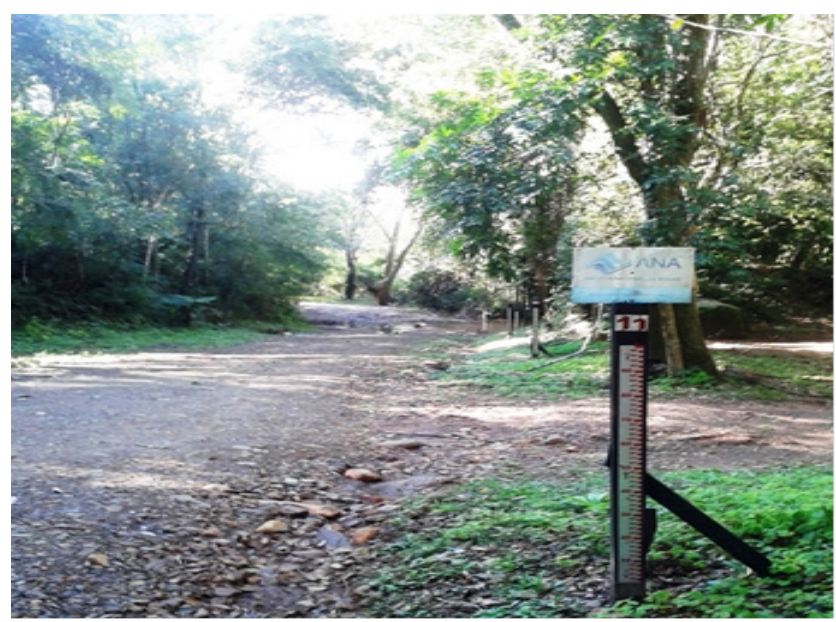

\section{Método}

Os procedimentos teórico-práticos deste trabalho são descritos cronologicamente e se baseiam parcialmente em alguns procedimentos matemáticos adotados por Kurek (2012).

Inicialmente, como vimos, obtiveram-se dados da milimetragem do nível do rio Jaguari por meio das réguas da ANA. Depois, se organizou o banco de dados por meio do Access. Os dados organizados no banco de dados referem-se à cota máxima registrada nas réguas milimétricas da ANA no município em cada mês, com 12 registros por ano.

Com a finalidade de realizar a análise dos dados, desenvolveu-se, por meio da linguagem de programação Visual Basic um aplicativo com a intenção de induzir a organização dos dados, com a geração de instruções Structured Query Language (SQL), e calcular a estimativa do tempo de retorno das inundações em função dos dados das réguas da ANA. Esse aplicativo foi denominado Pesquisas HidroWeb (Figura 2).

\section{Figura 2 - Vista do aplicativo Pesquisas HidroWeb}

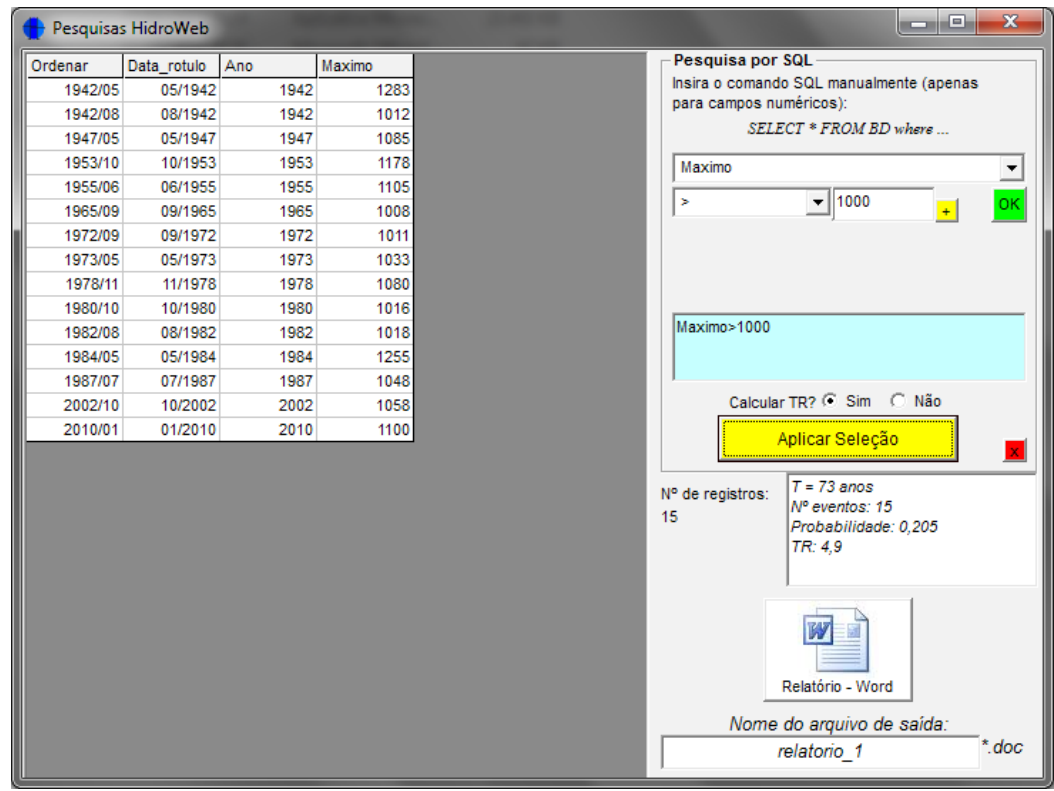


Assim, com o aplicativo, gerou-se a seleção dos dias com maiores níveis de água no rio Jaguari como, por exemplo, no que conta na Figura 2, mostrando a instrução SQL com o nível da régua tendo um valor máximo (no mês) superior a $1.000 \mathrm{~cm}(10 \mathrm{~m})$. Com o aplicativo, ainda, obteve-se o número de registros encontrados com aquela determinada instrução SQL, o tempo (T), em anos, total da análise (73 anos, de 1941 a 2014), a probabilidade de ocorrência do fenômeno para aquela cota, o tempo de retorno (TR), e, ainda a geração de um relatório com os dados.

Uma etapa posterior foi, a partir do aplicativo Pesquisas HidroWeb, gerar amostras reais do cálculo do tempo de retorno para que se estimassem as recorrências de inundações na área de estudo da forma que o analista achasse necessária.

Os dados foram analisados por meio de seis funções (estimadores), etapa metodológica feita no aplicativo Excel. Analisaram-se as funções logarítmica, linear, exponencial, polinomial de $2^{\text {a }}$ ordem, polinomial de 3 a ordem e exponencial.

Assim, foram geradas as estimativas para os tempo de retorno que fizeram parte da amostra ( $T R=1$ ano, $T R=2$ anos, $T R=3$ anos, $T R=4$ anos, $T R=5$ anos, $T R=10,4$ anos, $\mathrm{TR}=18,3$ anos, $\mathrm{TR}=24,3$ anos, $\mathrm{TR}=36,5$ anos e $\mathrm{TR}=73$ anos), e foi possível analisar o resíduo dos dados e verificar qual dos valores estimados mais se assemelha com as amostras, para que se possa apontar o melhor estimador do tempo de retorno.

\section{Resultados}

Com a geração de várias instruções SQL, foram obtidas as estimativas, as quais foram utilizadas como amostras (Quadro 1), para, que assim, fosse estimada a recorrência de inundações em Jaguari, processo realizado com a utilização de diferentes funções matemáticas do Excel. Ressalta-se, que a obtenção das amostras ocorreu no aplicativo Pesquisas HidroWeb.

\section{Quadro 1 - Dados obtidos com o uso do aplicativo Pesquisas HidroWeb para a criação das amostras}

\begin{tabular}{|c|c|c|}
\hline \multicolumn{3}{|l|}{ amostragem } \\
\hline tempo de retorno (anos) & $\operatorname{cota}(\mathrm{mm})$ & $n^{\circ}$ de eventos \\
\hline 1 & 810 & 74 \\
\hline 2 & 900 & 37 \\
\hline 3 & 969 & 24 \\
\hline 4 & 990 & 19 \\
\hline 5 & 1.000 & 15 \\
\hline 10,4 & 1.060 & 7 \\
\hline 18,3 & 1.100 & 5 \\
\hline 24,3 & 1.170 & 3 \\
\hline 36,5 & 1.200 & 2 \\
\hline 73 & 1.260 & 1 \\
\hline
\end{tabular}


Com as amostras obtidas, partiu-se para a construção dos gráficos com as seis funções matemáticas. Assim, para analisar com precisão e acurácia os dados, geraram-se as estimativas para vários tempos de retorno, conforme a Tabela 1.

$\mathrm{Na}$ Tabela 1, ainda foi analisado o coeficiente de correlação linear de Pearson $\left(\mathrm{R}^{2}\right)$, que caracteriza a qualidade do estimador perante as amostras; quanto mais próximo de 1 for $\circ R^{2}$, melhor é a correlação entre a amostra e o dado estimado. Os dados referentes às amostras estão em destaque no Quadro 1, e os valores estimados (por função), na Tabela 1.

\section{Tabela 1 - Dados gerais estimados}

\begin{tabular}{|c|c|c|c|c|c|c|}
\hline função & logarítmica & linear & exponencial & $\begin{array}{l}\text { polinomial } \\
\text { (2) }\end{array}$ & $\begin{array}{l}\text { polinomial } \\
\text { (3) }\end{array}$ & potência \\
\hline $\begin{array}{l}\text { tempo de } \\
\text { retorno } \\
\text { (anos) }\end{array}$ & $\operatorname{cota}(\mathrm{cm})$ & $\begin{array}{l}\text { cota } \\
(\mathrm{cm})\end{array}$ & $\operatorname{cota}(\mathrm{cm})$ & $\operatorname{cota}(\mathrm{cm})$ & $\operatorname{cota}(\mathrm{cm})$ & $\begin{array}{l}\text { cota } \\
(\mathrm{cm})\end{array}$ \\
\hline 1 & 833,00 & 957,76 & 954,31 & 909,00 & 884,40 & 844,10 \\
\hline 2 & 902,87 & 963,02 & 958,13 & 922,45 & 907,41 & 902,80 \\
\hline 3 & 943,74 & 968,28 & 961,97 & 935,66 & 929,26 & 939,02 \\
\hline 4 & 972,74 & 973,54 & 965,83 & 948,63 & 949,98 & 965,59 \\
\hline 5 & 995,23 & 978,80 & 969,70 & 961,35 & 969,58 & 986,72 \\
\hline 10 & $1.065,10$ & $1.005,10$ & 989,29 & $1.021,30$ & $1.051,70$ & $1.055,34$ \\
\hline 15 & $1.105,97$ & $1.031,40$ & $1.009,28$ & $1.075,15$ & $1.109,58$ & $1.097,68$ \\
\hline 20 & $1.134,97$ & $1.057,70$ & $1.029,66$ & $1.122,90$ & $1.146,20$ & $1.128,74$ \\
\hline 25 & $1.157,46$ & $1.084,00$ & $1.050,46$ & $1.164,55$ & $1.164,58$ & $1.153,44$ \\
\hline 30 & $1.175,84$ & $1.110,30$ & $1.071,69$ & $1.200,10$ & $1.167,70$ & $1.174,02$ \\
\hline 35 & $1.191,38$ & $1.136,60$ & $1.093,34$ & $1.229,55$ & $1.158,58$ & $1.191,70$ \\
\hline 40 & $1.204,84$ & $1.162,90$ & $1.115,42$ & $1.252,90$ & $1.140,20$ & $1.207,24$ \\
\hline 45 & $1.216,71$ & $1.189,20$ & $1.137,96$ & $1.270,15$ & $1.115,58$ & $1.221,11$ \\
\hline 50 & $1.227,33$ & $1.215,50$ & 1160,94 & $1.281,30$ & $1.087,70$ & $1.233,66$ \\
\hline 60 & $1.245,71$ & $1.268,10$ & $1.208,32$ & $1.285,30$ & $1.034,20$ & $1.255,67$ \\
\hline 70 & $1.261,25$ & $1.320,70$ & $1.257,63$ & $1.264,90$ & $1.003,70$ & $1.274,58$ \\
\hline 80 & $1.274,71$ & $1.373,30$ & $1.308,96$ & $1.220,10$ & $1.020,20$ & $1.291,20$ \\
\hline 90 & $1.286,58$ & $1.425,90$ & $1.362,38$ & $1.150,90$ & $1.107,70$ & $1.306,04$ \\
\hline 100 & $1.297,20$ & $1.478,50$ & $1.417,98$ & $1.057,30$ & $1.290,20$ & $1.319,45$ \\
\hline $\mathrm{R}^{2}$ & 0,985 & 0,722 & 0,667 & 0,901 & 0,934 & 0,974 \\
\hline
\end{tabular}

As funções obtidas para geração das estimativas estão expostas no Quadro 2, sintetizando os procedimentos matemáticos realizados. Já os gráficos de cada uma das funções estão expostos no Gráfico 1. 


\section{Quadro 2 - Equações utilizadas em cada função}

\begin{tabular}{|l|l|}
\hline função & equação \\
\hline logarítmica & $y=100,8 * \ln (x)+833$ \\
\hline linear & $y=5,260 x+952,5$ \\
\hline exponencial & $y=950,5 e^{0,004 x}$ \\
\hline polinomial $(2)$ & $y=-0,122 x^{2}+13,82 x+895,3$ \\
\hline polinomial $(3)$ & $y=0,004 x^{3}-0,605 x^{2}+24,80 x+860,2$ \\
\hline potência & $y=844,1 x^{0,097}$ \\
\hline
\end{tabular}

\section{Gráfico 1 - As funções}
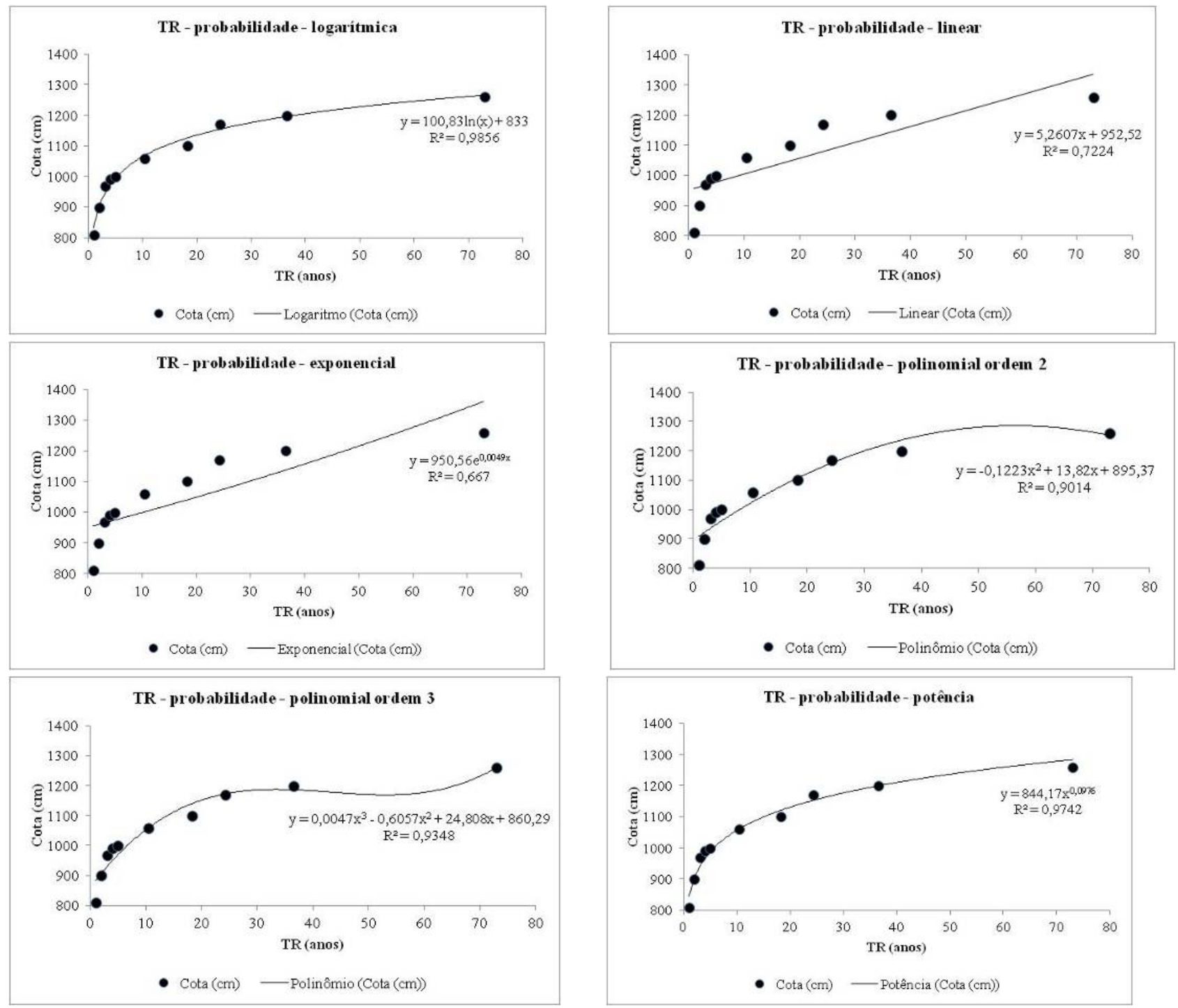

A fim de caracterizar os erros amostrais, também chamados resíduos, que são gerados a partir da diferença entre os dados estimados e as amostras, a Tabela 2 segmenta as referidas discrepâncias, bem como o somatório, a média e o desvio padrão em cada função, para concentrar os dados e verificar a acuidade de cada função. 
Os dados amostrais da Tabela 2 estão previamente referenciados no Gráfico 2.

Para definir a melhor função para gerar o tempo de retorno final, gerou-se ainda uma análise (Gráfico 3) que identifica o tempo de retorno estimado, de 1 a 100 anos.

Tabela 2 - Discrepâncias calculadas

\begin{tabular}{|l|l|l|l|l|l|l|}
\hline \multicolumn{6}{|l|}{ discrepância da amostra (resíduo em mm) } \\
\hline $\begin{array}{l}\text { tempo de } \\
\text { retorno (anos) }\end{array}$ & logarítmica & linear & exponencial & polinomial (2) & polinomial (3) & potência \\
\hline 1 & 23,00 & 147,76 & 144,31 & 99,00 & 74,40 & 34,10 \\
\hline 2 & 2,87 & 63,02 & 58,13 & 22,45 & 7,41 & 2,80 \\
\hline 3 & 25,26 & 0,72 & 7,03 & 33,34 & 39,74 & 29,98 \\
\hline 4 & 17,26 & 16,46 & 24,17 & 41,37 & 40,02 & 24,41 \\
\hline 5 & 4,77 & 21,20 & 30,30 & 38,65 & 30,43 & 13,28 \\
\hline 10,4 & 9,05 & 52,80 & 69,13 & 34,17 & 2,82 & 0,63 \\
\hline 18,3 & 26,02 & 51,24 & 77,31 & 7,35 & 35,95 & 19,06 \\
\hline 24,3 & 15,40 & 89,68 & 122,47 & 10,91 & 7,01 & 19,74 \\
\hline 36,5 & 4,39 & 55,51 & 100,09 & 37,20 & 46,10 & 3,43 \\
\hline 73 & 5,48 & 76,48 & 12,82 & 5,98 & 257,38 & 19,78 \\
\hline somatório & 133,50 & 574,87 & 645,75 & 330,41 & 541,25 & 167,22 \\
\hline média & 13,35 & 57,49 & 64,58 & 33,04 & 54,13 & 16,72 \\
\hline desvio padrão & 9,18 & 41,98 & 47,13 & 26,80 & 74,62 & 11,56 \\
\hline
\end{tabular}

\section{Gráfico 2 - Resíduos tabulados}

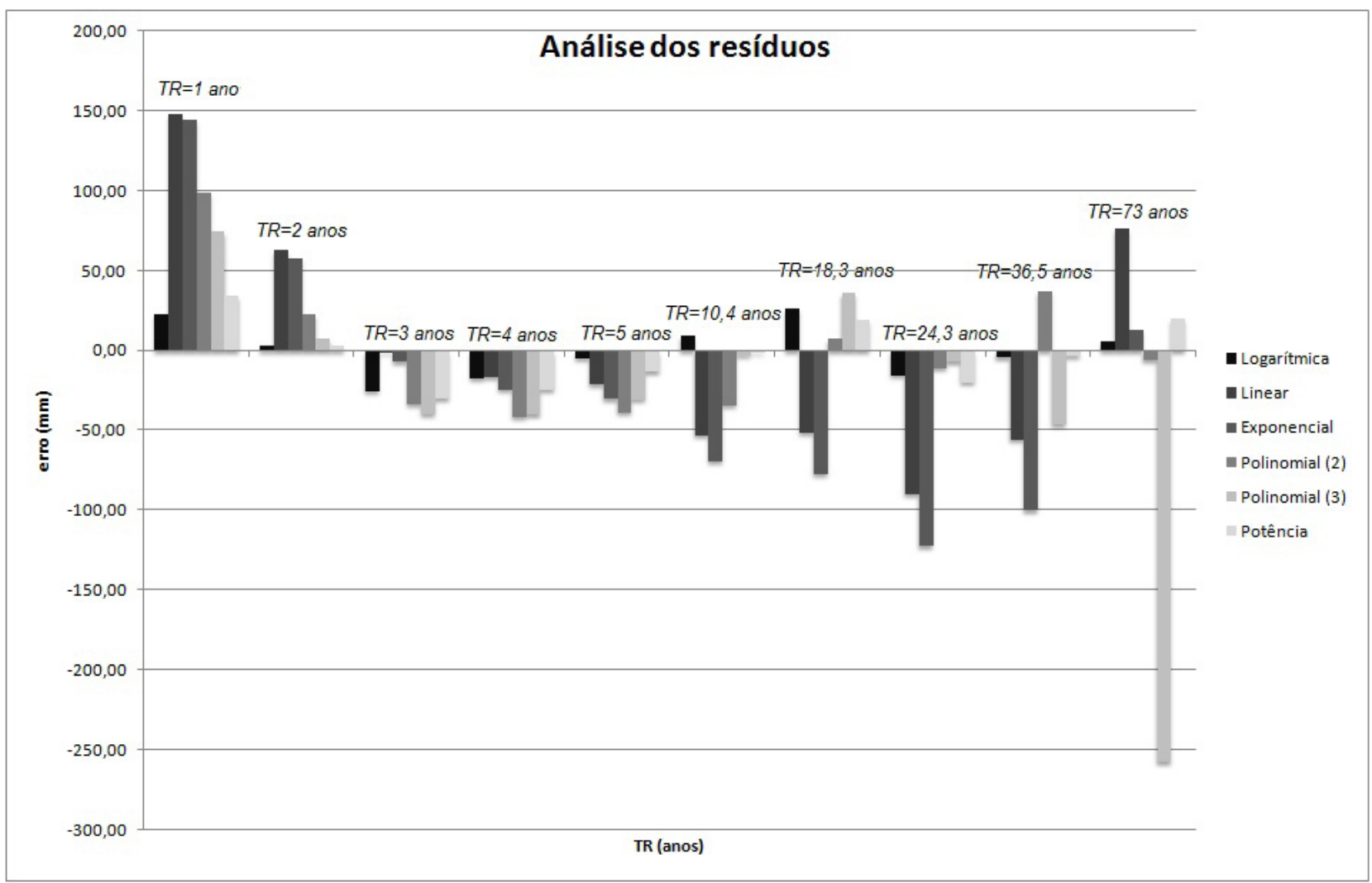




\section{Gráfico 3 - Tempo de retorno estimado com todas as funções}

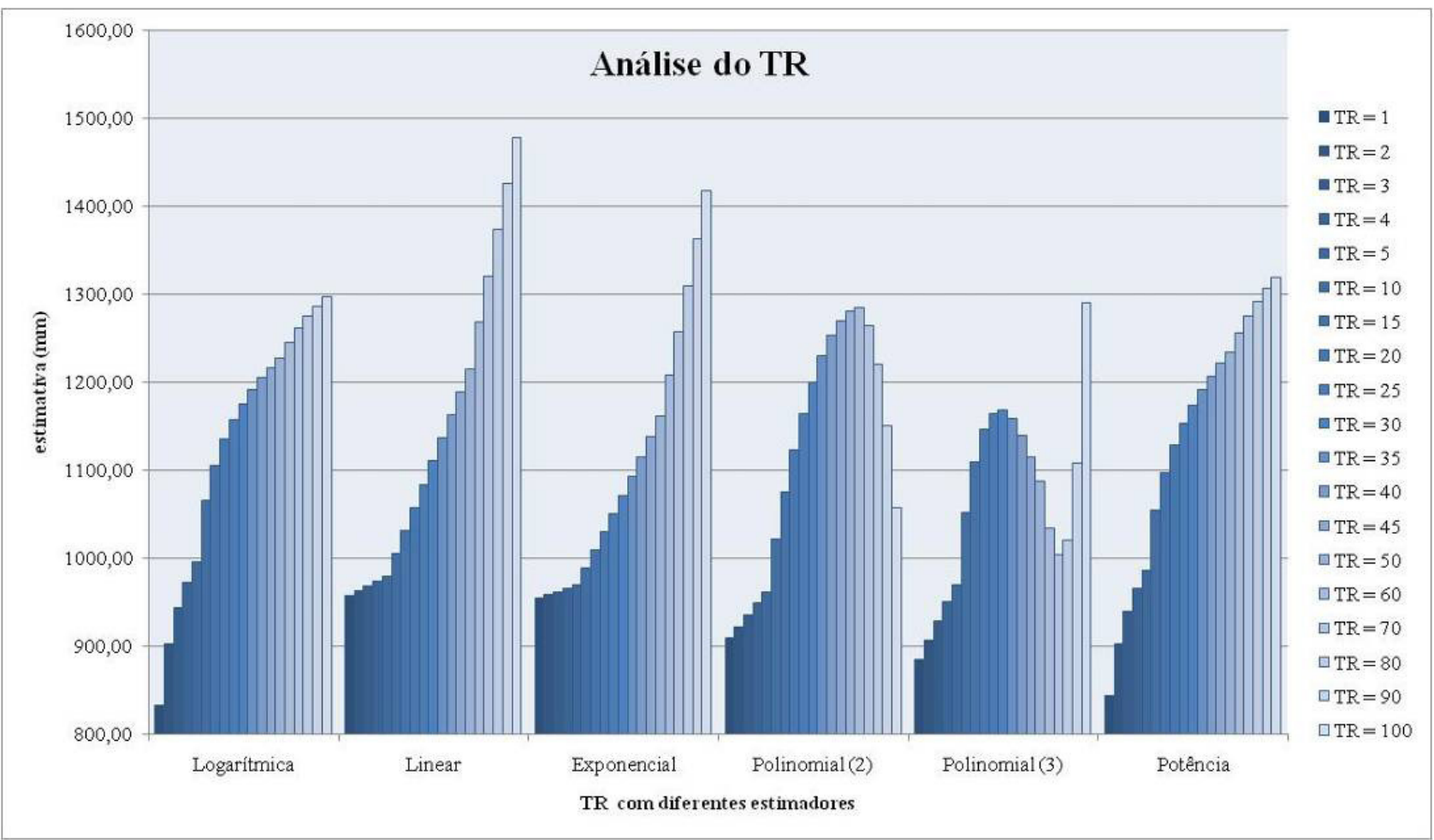

\section{Discussão}

A partir dos resultados obtidos, discute-se qual das funções representa melhor a estimativa do tempo de recorrência de inundações em Jaguari-RS.

Perante a análise da Tabela 1, verificando o $\mathrm{R}^{2}$, notou-se que as maiores correlações foram encontradas para as funções logarítmica e de potência, com os valores de 0,985 e 0,974, respectivamente. As funções polinomiais de $2^{\text {a }}$ e $3^{a}$ ordem resultaram em altas correlações de valores expressivos de cerca de 0,9. Com resultados de $R^{2}$ menos expressivos estiveram as funções linear (com 0,722) e exponencial (com 0,607).

Explorando as informações da Tabela 2, com foco no desvio padrão dos dados, verificaram-se dois agrupamentos de dados. Novamente as funções logarítmicas e de potência geraram os melhores resultados, com baixos desvios padrões de 9, 18 e 11,56, respectivamente. Os demais resultados são bem menos expressivos, com 26,8 (polinomial de 2o grau), 41, 98 (linear), 47,13 (exponencial), 74,6 (polinomial de 3o grau).

Já no Gráfico 3, por meio de uma análise visual, podem-se eliminar definitivamente duas das funções: as polinomiais de 2a e $3^{a}$ ordem. Isso se deve ao fato de os dados ora ascenderem, ora diminuírem, gerando um padrão anormal para a variação do tempo de retorno de uma inundação. Destaca-se que um tempo de retorno superior não pode ter uma cota de alague menor do que um inferior. As demais variações até então podem ser consideradas normais, pois tendem a aumentar a cota na medida em que aumenta o tempo de retorno.

Após a exclusão de duas das seis funções, eliminaram-se ainda as funções linear e exponencial. Dois motivos explicam esse fato. $\bigcirc$ primeiro é uma análise minuciosa do Gráfico 3 , onde se nota uma alta similaridade da estimativa para os tempos de retorno baixos e com a 
maior diferença das estimativas nos maiores tempos de recorrência. $\bigcirc$ segundo é a análise do $\mathrm{R}^{2}$, sendo notória a baixa correlação entre as amostras e os dados estimados, se bem que o alto desvio padrão também oriente a deficiência das referidas funções.

Assim sendo, após essas análises, consideraram-se as funções logarítmica e de potência como as mais condizentes para a realização de estimativas de tempo de retorno, pois apresentaram os melhores resultados para todos os requisitos em análise. Porém, como a ideia do trabalho é definir uma das funções como a melhor estimadora do tempo de retorno, optou-se pela função logarítmica, por ter a maior correlação $\left(R^{2}\right)$ e o menor desvio padrão.

Assim, o Gráfico 4 delimita o tempo de retorno das inundações em Jaguari-RS, informações que foram determinadas pelo uso da função logarítmica. Na Tabela 3, há um resumo dos valores estimados dos tempos de retorno de 1, 5, 10, 50 e 100 anos.

\section{Gráfico 4 - Tempo de retorno final estimado com a função logarítmica}

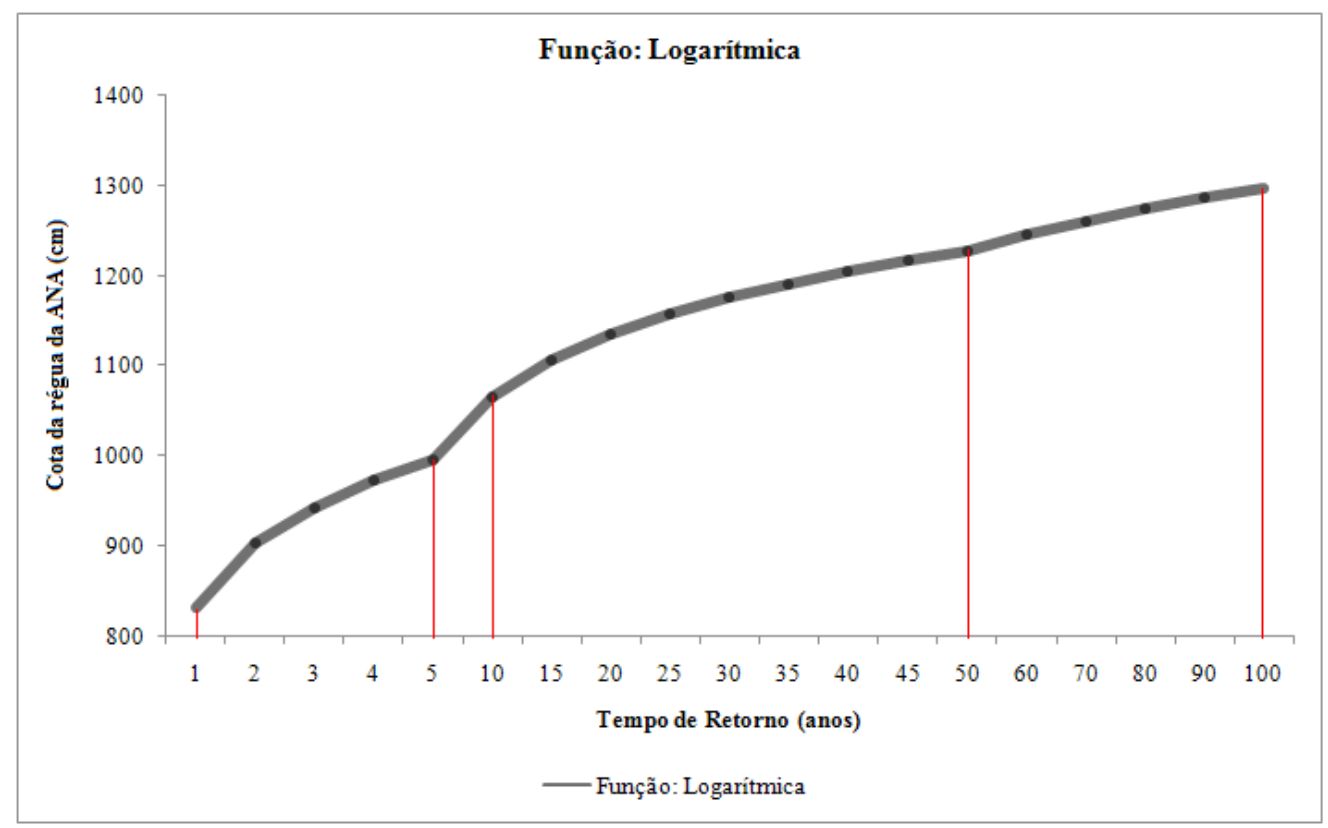

fonte: Organizado pelos autores.

\section{Tabela 3 - Tempo de retorno estimado com a função logarítmica}

\begin{tabular}{|l|l|}
\hline tempo de retorno (anos) & cota $(\mathrm{cm})$ \\
\hline 1 & 833,00 \\
\hline 5 & 995,23 \\
\hline 10 & $1.065,10$ \\
\hline 50 & $1.227,33$ \\
\hline 100 & $1.297,20$ \\
\hline
\end{tabular}

Com o intuito de buscar a correlação dos dados já ocorridos, perante os tempos de retorno estipulados, a Figura 3 ilustra alguns cenários de inundações no município, juntamente com a correlação temporal. 
Figura 3 - Eventos de inundação em Jaguari em 1941 (a), 1984 (b) e 2014 (c e d)

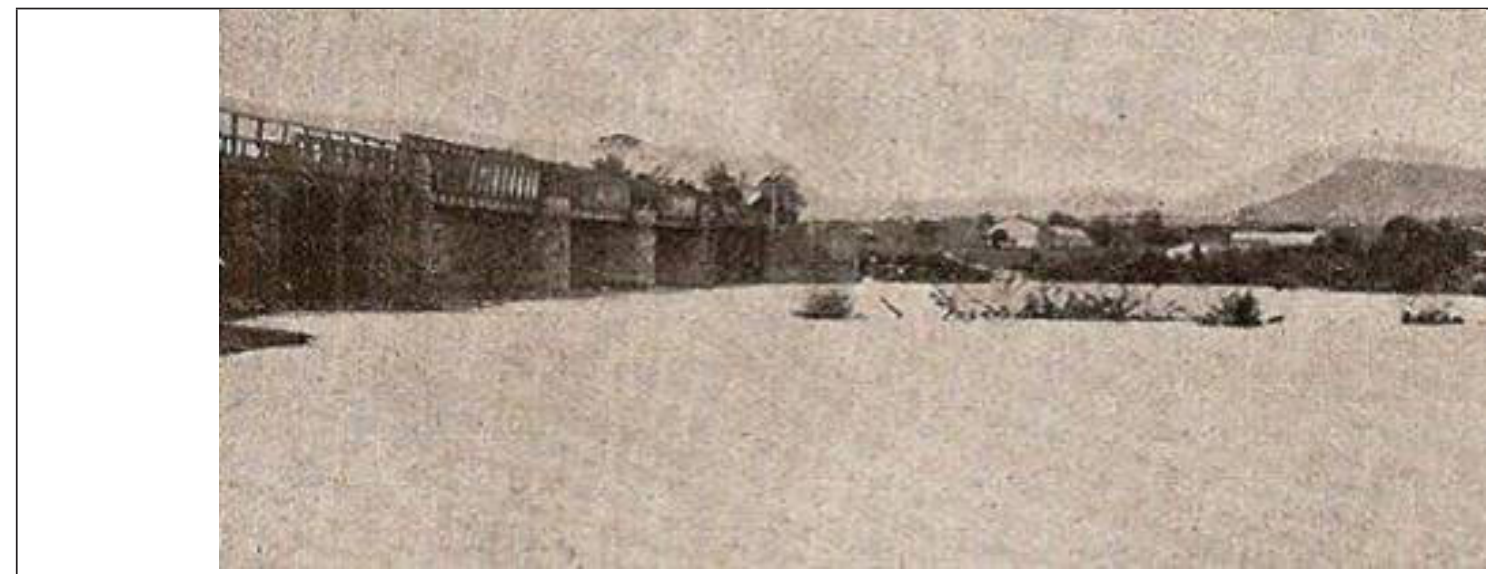

(a)

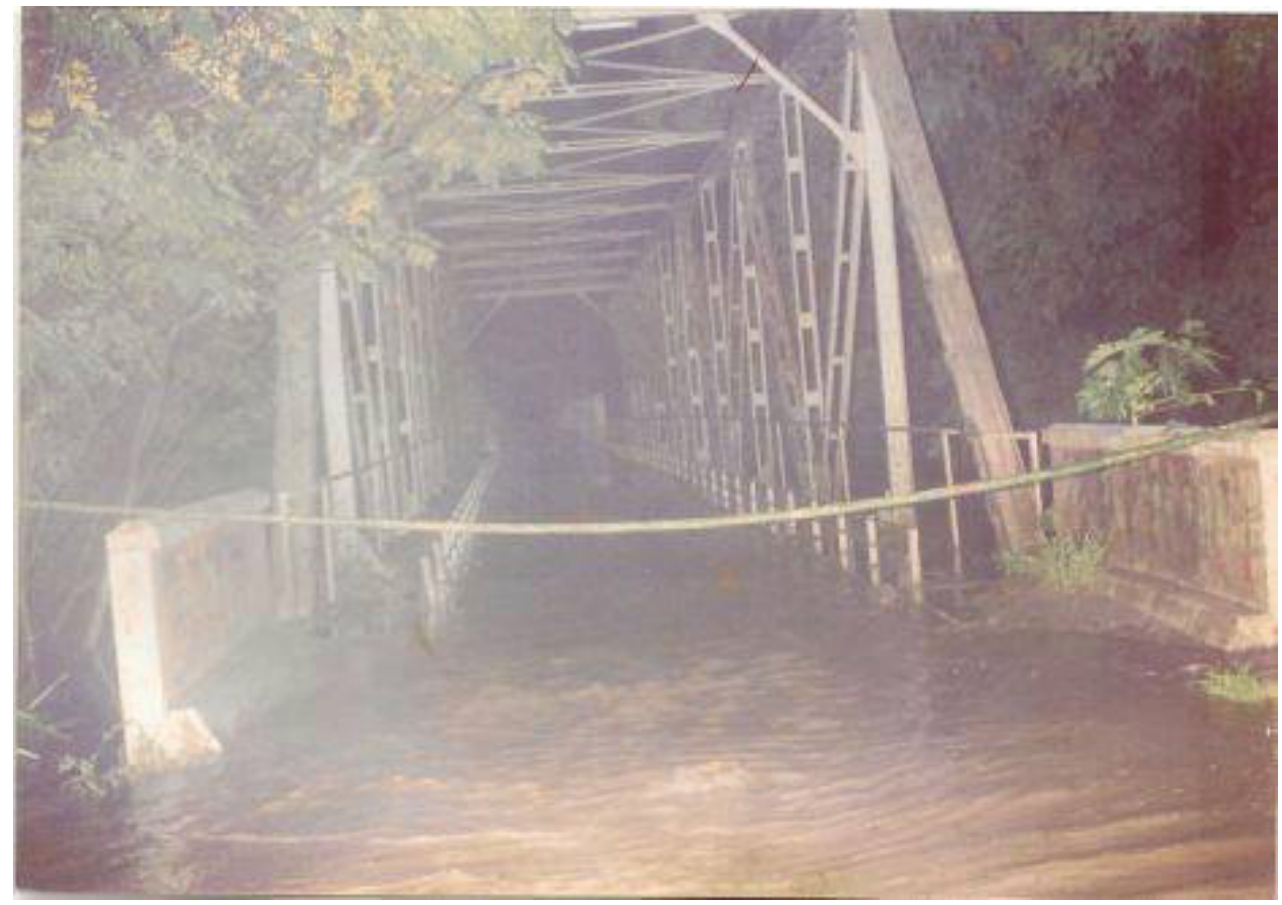

(b)

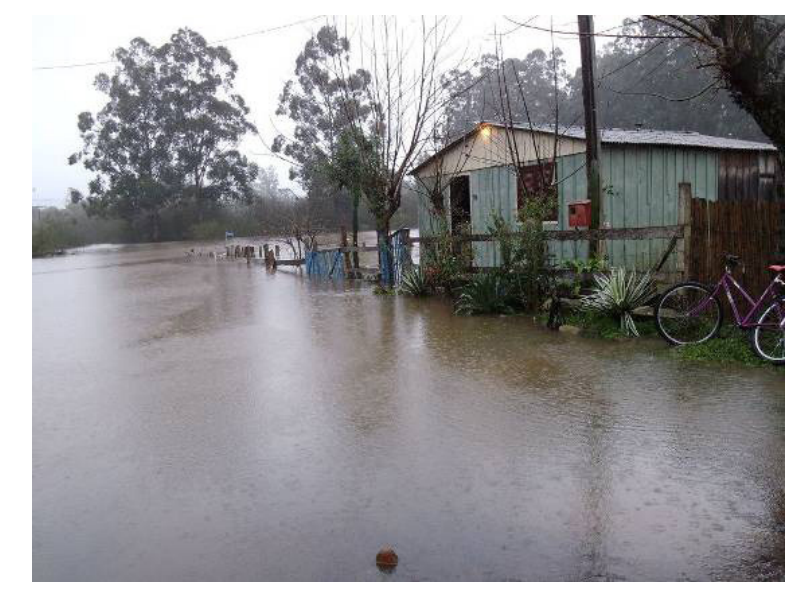

(c)

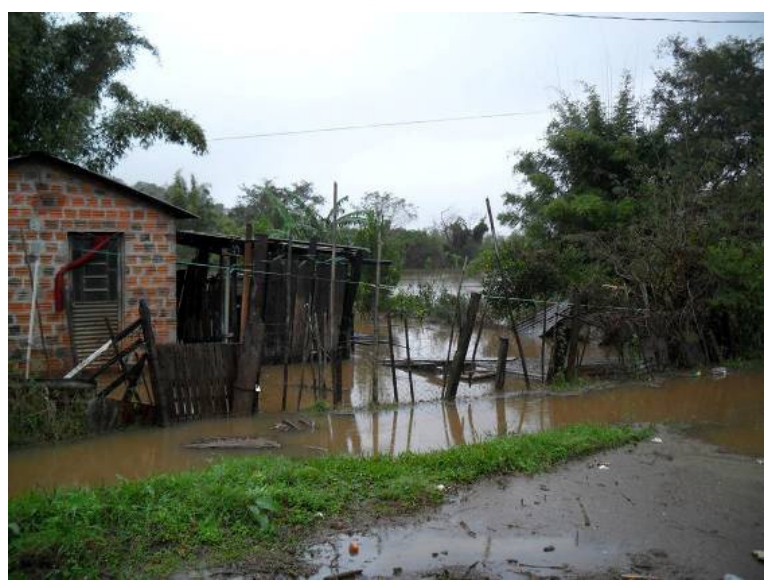

(d)

fonte: Museu Municipal (a, b), Miguel Monte (c), Cristiano S. Moraes (d). 


\section{Considerações finais}

Considera-se de extrema importância para trabalhos futuros a metodologia envolvente para estimar o tempo de retorno das inundações no município de Jaguari.

O uso do aplicativo Pesquisas HidroWeb se mostrou válido, pois foram geradas amostras do tempo de retorno de inundações na área de estudo a partir de dados das réguas da ANA.

A aplicação de funções matemáticas também foi muito importante, pois resultou na meIhor estimativa possível do tempo de retorno das inundações na área de estudo. Essa análise é fundamental, pois o tempo de retorno é base para trabalhos posteriores visando o zoneamento das áreas de risco de inundação.

Destaca-se ainda que a delimitação correta do tempo de retorno é uma etapa inicial para cartografar as áreas de risco a inundação na área de estudo. Finalmente, a metodologia apresentada aqui pode servir de base a outros trabalhos técnicos que visem estimar tempo de retornos para outros lugares que tenham réguas da ANA.

\section{Referências}

ANA. AGÊNCIA NACIONAL DE ÁGUAS. Atlas de vulnerabilidade a inundações.

Disponível em: http://www.ana.gov.br/bibliotecavirtual/arquivos/20131002104753_ Plotagem_RS_A0.pdf. Acesso em: 12 nov. 2017.

ANEAS DE CASTRO, S. D. A. Riesgos y peligros: una visión desde la geografía. Scripta

Nova - Revista Electrónica de Geografía y Ciencias Sociales, Universidad de Barcelona, 15 marzo 2000.

AYALA-CARCEDO, F. J. La ordenación del territorio en la prevención de catástrofes naturales y tecnológicas: bases para un procedimiento técnico-administrativo de evaluación de riesgos para la población. Boletín de la A.G.E. , Instituto Geológico Y Minero de España, n. 30, p. 37-49, 2000.

CÂMARA, G.; MONTEIRO, A. M. Geotecnologias em um novo paradigma de desenvolvimento. Divisão de Processamento de Imagens - Inpe. Nepo/Unicamp, abr. 2000. Disponível em: http://www.dpi.inpe.br/geopro/apresentacoes/inpe_nepo.pdf. Acesso em: 20 mar.2018. Antônio Miguel

CAMPOS, S. J. A. M.; STEFANI, F. L.; PAULON, N.; FACCINI, L. G.; BITAR, O. Y. Cartas de suscetibilidade à inundação. In: CONGRESSO BRASILEIRO DE GEOLOGIA DE ENGENHARIA E AMBIENTAL, 15., 2015, Bento Gonçalves, RS. Anais... Bento Gonçalves: Associação Brasileira de Geologia de Engenharia Ambiental (ABGE), 2015.

CARVALHO, C. S.; MACEDO, E. S.; OGURA, A. T. Mapeamento de riscos em encostas e margem de rios. Brasilia: Ministério das Cidades/Instituto de Pesquisas Tecnológicas (IPT), 2007.

CARVALHO, D. W.; DAMACENA, F. D. L. Direito dos desastres. Porto Alegre: Livraria do Advogado, 2013. 
CASTRO, A. L. C. Glossário de defesa civil: estudos de riscos e medicina de desastres. $2^{a}$ ed. rev. ampl. Brasilia, DF: Ministério do Planejamento e Orçamento/Secretaria Especial de Políticas Regionais/Departamento de Defesa Civil, 1998.

CERCA de 30 famílias seguem desabrigadas em Jaguari. Correio do Povo, Porto Alegre, 21 jan.2010. Disponívelem:http://www.correiodopovo.com.br/Noticias/?Noticia=88280. Acesso em: 17 fev. 18.

CUNHA, S.; TAVEIRA-PINTO, F. Aplicação de uma metodologia de análise de risco de inundações à zona ribeirinha do Peso da Régua. In: JORNADA DE HIDRÁULICA, RECURSOS HÍDRICOS E AMBIENTE, 6., 2011, Porto, PT: FEUP. Disponível em: https://paginas.fe.up.pt/ shrha/publicacoes/pdf/JHRHA_6as/10_SCunha_ Aplica\%C3\%A7\%C3\%A3o.pdf. Acesso em: 11 jan. 2018.

DIÁRIO de Santa Maria noticia a enchente em Jaguari. Blog Rafael Nemitz, Santiago, RS, 4 out. 2012. Disponível em: http://www.rafaelnemitz.com/2012/10/diario-de-santa-maria-noticia-enchente.html. Acesso em: 17 fev. 2018.

ENCHENTE em Jaguari: rio que corta o município atinge 10 metros acima do nível normal. Blog Rafael Nemitz, Santiago, RS, 24 jul. 2014. Disponível em: http://www.rafaelnemitz.com/2014/07/enchente-em-jaguari-rio-que-corta-o.html\#.U-uNy_k919E. Acesso em: 13 ago. 2017.

IBGE. INSTITUTO BRASILEIRO DE GEOGRAFIA E ESTATÍSTICA. Rio Grande do Sul, Jaguari, 2010a. Disponível em: http://www.ibge.gov.br/cidadesat/xtras/perfil. php?codmun=431110. Acesso em: 11 jan. 2018.

IPT. INSTITUTO DE PESQUISAS TECNOLÓGICAS. Cartas de suscetibilidade a movimentos gravitacionais de massa e inundações - 1:25.000. Brasilia, DF, 2016.

IPT. INSTITUTO DE PESQUISAS TECNOLÓGICAS. Manual de uso e ocupação das encostas. São Paulo, 1991.

IG. INSTITUTO GEOLÓGICO DE SÃO PAULO. Mapeamento de áreas de risco a inundação no estado de São Paulo, 24 jul. 2012. Disponível em: http:// pt.slideshare.net/igeologicosp/app-semi-sorocaba-ig. Acesso em: 13 maio 2018.

KHATIBI, R. Evolutionary systemic modeling of practices on flood risk. Journal of Hydrology, v. 401, n. 1, p. 36-52, 2011.

KUREK, R. K. M. Avaliação do tempo de retorno nos níveis das inundações no vale do Taquari-RS. Trabalho de Conclusão de Curso (Bacharelado em Engenharia Ambiental) - Centro Universitário Univates, Lajeado, 2012.

MONTEIRO, L. R.; KOBIYAMA, M. Proposta de metodologia de mapeamento de perigo de inundação. Rega, vol. 10, n. 2, p. 13-25, jul./dez. 2013.

RECKZIEGEL, B. W. Levantamento dos desastres desencadeados por eventos naturais adversos no estado do Rio Grande do Sul no período de 1980 a 2005. Dissertação (Mestrado em Análise Ambiental e Dinâmica Espacial) - Centro de Ciências Naturais e Exatas, Universidade Federal de Santa Maria, Santa Maria, 2007. 2v. 
RIBEIRO, C. B. M.; LIMA, R. N. S. Simulação de inundações urbanas a partir da integração de técnicas de geoprocessamento à modelagem hidráulica e hidrológica. Revista de Geografia - PPGEO, v. 2, n. 1, p. 1-9, 2011.

ROBAINA, L. E. S.; TRENTIN, R. (Org.). Desastres naturais no Rio Grande do Sul. Santa Maria, RS: Ed. UFSM, 2013.

SANTOS, R. F. (Org.). Vulnerabilidade ambiental: desastres naturais ou fenômenos induzidos? Brasília: Ministério do Meio Ambiente, 2007.

TOMINAGA, L. K.; SANTORO, J.; AMARAL, R. Desastres naturais: conhecer para prevenir. São Paulo: IG/Secretaria do Meio Ambiente/Governo do Estado de São Paulo, 2009.

TUCCI, C. E. M. (Org.). Hidrologia: ciência e aplicação. São Paulo/Porto Alegre: Edusp/ UFRGS, 1993. cap. 16. p. 621-658.

TUCCI, C. E. M.; BERTONI, J. C. (Org.). Inundações urbanas na América do Sul. Porto Alegre: Associação Brasileira de Recursos Hídricos, 2003. Disponível em: http:// www.eclac.cl/samtac/noticias/documentosdetrabajo/5/23335/InBr02803.pdf. Acesso em: 5 jun. 2017. 